\title{
EL EJERCICIO TRANSFRONTERIZO DE LA ACCIÓN CIVIL DE RECTIFICACIÓN
}

\section{THE CROSS-BORDER EXERCISE OF THE CIVIL REPLY ACTION}

\author{
JAVIER Martínez CALVo \\ Doctor en Derecho. Miembro Colaborador del Grupo de Investigación Ius Familiae \\ Universidad de Zaragoza
}

Recibido: 13.04.2020 / Aceptado: 04.05.2020

DOI: https://doi.org/10.20318/cdt.2020.5673

\begin{abstract}
Resumen: Pese a las iniciativas de armonización que se han llevado a cabo desde algunos foros internacionales, la regulación del derecho de rectificación se encuentra dispersa en los ordenamientos jurídicos de los distintos Estados, que lo han configurado de modo diverso. Ello dificulta el ejercicio transfronterizo de la acción civil de rectificación y plantea algunos problemas para la determinación de la competencia judicial internacional y de la ley aplicable, dado que el Derecho Internacional Privado no se refiere de forma expresa al derecho de rectificación.

Palabras clave: Derecho de rectificación, Derecho Internacional, competencia judicial internacional, ley aplicable.

Abstract: Despite the initiatives of harmonization that have been carried out from some international forums, the regulation of the right of reply is dispersed in the legal systems of the different States, which have configured it in different ways. This makes the cross-border exercise of the civil reply action difficult and presents some problems for the determination of international jurisdiction and applicable law, since Private International Law does not expressly refer to the right of rectification.

Keywords: Right of reply, International Law, international jurisdiction, applicable law.

Sumario: I. Introducción. II. El derecho de rectificación en la normativa supranacional. III. Dispersión normativa y falta de armonización de la regulación del derecho de rectificación en los ordenamientos nacionales. IV. El ejercicio transfronterizo de la acción de rectificación desde la perspectiva del Derecho Internacional Privado. 1. Competencia judicial. A) Determinación de la competencia judicial internacional. B) Determinación de la competencia interna de los tribunales españoles. 2. Ley aplicable. VI. A modo de conclusión.
\end{abstract}

\section{Introducción}

1. Cuando una persona resulta perjudicada por la publicación de informaciones falsas o inexactas, nuestro ordenamiento jurídico pone a su disposición diferentes mecanismos de reacción (tanto en el ámbito civil ${ }^{1}$ como en el penal ${ }^{2}$ y el administrativo ${ }^{3}$ ). Entre los mecanismos civiles se encuentra el

${ }^{1}$ El objetivo de esta acción será el restablecimiento del perjudicado en el pleno disfrute de sus derechos, con la declaración de la intromisión sufrida, el cese inmediato de la misma y la reposición del estado anterior, así como el resarcimiento de los perjuicios sufridos a través de la correspondiente indemnización (artículo 9.2 de la Ley Orgánica 1/1982, de 5 de mayo, de protección civil del derecho al honor, a la intimidad personal y familiar y a la propia imagen).

${ }^{2}$ A través del ejercicio de una acción por injurias (artículos 208 y ss. del Código Penal) o calumnias (artículos 205 y ss. del Código Penal).

${ }^{3} \mathrm{Al}$ tratarse de derechos fundamentales, podrá recurrirse al procedimiento especial previsto en los artículos 114 y ss. de la Ley 29/1998, de 13 de julio, reguladora de la Jurisdicción Contencioso-administrativa 
denominado derecho de rectificación, que cuenta con una regulación específica, contenida en la Ley Orgánica 2/1984, reguladora del derecho de rectificación (en adelante: LODR).

2. De acuerdo con el artículo primero de dicha norma, el derecho de rectificación puede definirse como la facultad que tiene toda persona, física o jurídica, para solicitar la rectificación de la información difundida en un medio de comunicación social, de hechos que le aludan, que considere inexactos y cuya divulgación pueda causarle perjuicio. Por tanto, su objeto es reparar el daño causado por una información errónea, permitiendo al aludido por ella que ofrezca otra versión sobre los mismos hechos.

3. Aunque el articulo 1 LODR limita la posibilidad de ejercer el derecho de rectificación únicamente ante información publicada en un medio de comunicación social, esta materia se ha visto reformada por la Ley Orgánica 3/2018, de Protección de Datos Personales y garantía de los derechos digitales (en adelante: LOPDP), que ha extendido la posibilidad de ejercer dicha acción frente a información difundida en redes sociales o servicios equivalentes.

4. Ahora bien, aun sin negar la buena intención del legislador, lo cierto es que más allá de ampliar la posibilidad de ejercer el derecho de rectificación frente a informaciones publicadas en la red, la regulación que ofrece el artículo 85 LOPDP es muy somera y, prácticamente, se limita a realizar una remisión en bloque a la regulación contenida en la Ley Orgánica 2/1984, reguladora del derecho de rectificación. Por ello, es discutible que resulte suficiente para adaptar el derecho de rectificación al escenario actual, en el que internet ha revolucionado el sector de las comunicaciones y la mayoría de la información se difunde a través de este medio.

5. La internacionalización de las comunicaciones, favorecida por el desarrollo de internet, exige nuevas soluciones que vayan más allá de las legislaciones nacionales ${ }^{4}$. Al respecto, como vamos a ver, desde las distintas instancias internacionales se han llevado a cabo numerosas iniciativas con objeto de armonizar la regulación del derecho de rectificación. Pero, aunque ha habido algunos avances, actualmente dicha regulación se encuentra dispersa en los ordenamientos internos de los distintos Estados. Ello puede provocar algunos problemas para el ejercicio de la acción de rectificación, especialmente desde el punto de vista del Derecho Internacional Privado.

6. En las siguientes líneas se analizarán todas estas cuestiones. Pero antes, para evitar confundir al lector, conviene advertir desde este momento que las expresiones utilizadas en el ámbito internacional para referirse al derecho que nos ocupa son variadas: en ocasiones se habla de derecho de rectificación, pero en otras de derecho de réplica o de derecho de respuesta. Y lo mismo ocurre en el ámbito comparado. En cualquier caso, con objeto de unificar, me referiré a él como derecho de rectificación, por ser la expresión que recoge el ordenamiento jurídico español.

\section{El derecho de rectificación en la normativa supranacional}

7. En el ámbito del Derecho Internacional, el primer texto en el que puede considerarse incluido el derecho de rectificación es la Declaración Universal de Derechos Humanos de 1948. Aunque no lo menciona de forma expresa, puede extraerse de su artículo $19^{6}$, que señala que "todo individuo tiene

\footnotetext{
${ }^{4}$ No podemos olvidar que la expansión de internet ha hecho que las fronteras físicas entre los ciudadanos desaparezcan. Como señala Benito García, «el derecho de la información será cada vez más un derecho internacional de la información» (vid. J.M. BENIto GARCÍA, "El derecho de rectificación electrónica: una forma interactiva de participación", en AA.VV.: La ética y el derecho de la información en los tiempos del postperiodismo, Valencia: Fundación COSO de la Comunidad Valenciana para el Desarrollo de la Comunicación y la Sociedad, 2007, p. 164).

${ }^{5}$ Disponible en: https://www.un.org/es/universal-declaration-human-rights/ (fecha última consulta: 01/04/2020).

${ }^{6} \mathrm{Vid}$. A. Rosas Martínez, “¿Derecho de rectificación, derecho de respuesta o derecho de réplica?”, Derecho Comparado de la Información, julio-diciembre, 2011, p. 90
} 
derecho a la libertad de opinión y de expresión; este derecho incluye el de no ser molestado a casusa de sus opiniones, el de investigar y recibir informaciones y opiniones, y el de difundirlas sin limitación de fronteras, por cualquier medio de expresión". Así mismo, el artículo 12 dispone que "nadie será objeto de injerencias arbitrarias en su vida privada, su familia, domicilio o su correspondencia, ni de ataques a su honra o a su reputación. Toda persona tiene derecho a la protección de la ley contra tales injerencias o ataques".

8. Sí se refiere expresamente al derecho de rectificación la Convención sobre el Derecho Internacional de Rectificación ${ }^{7}$, que fue aprobada por la Asamblea General de la ONU el 16 de diciembre de 1952 y que entró en vigor el 24 de agosto de 1962. No obstante, se trata de un derecho pensado para combatir la difusión de informaciones falsas que puedan ser perjudiciales para las relaciones amistosas entre Estados, como expresamente reconoce en su exposición de motivos. En congruencia con ello, la legitimación activa y pasiva de la acción de rectificación prevista en este Tratado corresponde exclusivamente a los Estados parte. Así se deduce de su artículo tercero, que en su primer párrafo señala que "dentro del plazo más breve posible, y en todo caso dentro de los cinco días hábiles siguientes a la fecha de recibo de un comunicado transmitido con arreglo a las disposiciones del artículo II, todo Estado Contratante, sea cual fuere su opinión respecto de los hechos de que se trate deberá: distribuir el comunicado a los corresponsales y agencias de información que ejerzan actividades en su territorio, por las vías habitualmente utilizadas para la transmisión de informaciones sobre asuntos internacionales destinadas a la publicación(...)"; y en su segundo punto dispone que "en caso de que un Estado Contratante no cumpla la obligación que le impone este artículo respecto de un comunicado de otro Estado Contratante, este último podrá aplicar el principio de reciprocidad y observar la misma actitud cuando el Estado que haya faltado a sus obligaciones le presente ulteriormente un comunicado". La importancia de esta norma radica, sobre todo, en el hecho de constituir la primera referencia expresa al derecho de rectificación en el ámbito del Derecho Internacional. Al margen de ello, lo cierto es que este Tratado cuenta con muy pocos estados signatarios (entre los que no se encuentran algunas de las principales potencias, como Estados Unidos o Rusia) y presenta importantes carencias, como la inexistencia de consecuencia alguna para el supuesto de que alguno de los Estados parte no cumpla con sus obligaciones, más allá de facultar al Estado perjudicado para que mantenga una actitud de reciprocidad y niegue también una eventual solicitud de rectificación procedente del primero. Debido al fracaso del Tratado, la Organización de las Naciones Unidas comenzó a recomendar a los Estados que celebraran acuerdos regionales entre países vecinos que permitan regular el derecho de rectificación más allá de las fronteras nacionales ${ }^{8}$.

9. También ha previsto expresamente el derecho de rectificación la Convención Americana de Derechos Humanos de 22 de noviembre de $1969^{9}$, que, esta sí, legitima a los particulares para su ejercicio. Al respecto, en su artículo 14 establece que "toda persona afectada por informaciones inexactas $o$ agraviantes emitidas en su perjuicio, a través de medios de difusión legalmente reglamentados y que se dirijan al público en general, tiene derecho a efectuar por el mismo órgano de difusión su rectificación o respuesta en las condiciones que establezca la ley". La Convención Americana de Derechos Humanos es, todavía hoy, el único texto internacional de Derechos Humanos en referirse de forma específica al derecho de rectificación.

10. En el ámbito del Consejo de Europa, el Convenio Europeo de Derechos Humanos de $1950^{10}$ no menciona expresamente el derecho de rectificación, pero, al igual que hemos visto que ocurre con la

\footnotetext{
${ }^{7}$ Disponible en: http://hrlibrary.umn.edu/instree/spanish/sulcirc.html (fecha última consulta: 01/04/2020).

8 Vid. P. FARRÉ LóPEZ, “El Derecho de rectificación en la Organización de Naciones Unidas”, La Ley, 4275, 2010, p. 2 (esta doctrina forma parte del libro "El derecho de rectificación. Un instrumento de defensa al poder de los medios", edición $n^{\circ} 1$, Editorial La Ley, Madrid, octubre 2008).

${ }^{9}$ Disponible en: https://www.oas.org/dil/esp/1969_Convenci\%C3\%B3n_Americana_sobre_Derechos_Humanos.pdf (fecha última consulta: 01/04/2020).

${ }^{10}$ Disponible en: https://www.echr.coe.int/Documents/Convention_SPA.pdf (fecha última consulta: 01/04/2020).
} 
Declaración Universal de Derechos Humanos, puede extraerse de varios de los principios que recoge. En este sentido, en su artículo 10.1 establece que "toda persona tiene derecho a la libertad de expresión. Este derecho comprende la libertad de opinión y la libertad de recibir o de comunicar informaciones o ideas, sin que pueda haber injerencia de autoridades públicas y sin consideración de fronteras(...)". Además, en su artículo 8.1 señala que "toda persona tiene derecho al respeto de su vida, vida privada y familiar, de su domicilio y de su correspondencia(...)". Este reconocimiento implícito del derecho de rectificación en el Convenio Europeo de Derechos Humanos tiene dos importantes consecuencias: la primera es que podrá hacerse valer en países miembros del Consejo de Europa que no lo hayan regulado expresamente, y, la segunda, que legitimará a los particulares para interponer recurso ante el Tribunal Europeo de Derechos Humanos, en caso de que dicho derecho resulte vulnerado ${ }^{11}$.

11. Además de la referencia implícita al derecho de rectificación que recogen los artículos 8.1 y 10.1 del Convenio Europeo de Derechos Humanos de 1950, se han ido promulgando en el seno del Consejo de Europa algunos textos que aluden a este derecho:

12. El primero de ellos fue la Resolución 582 (1970) de la Asamblea Consultiva del Consejo de Europa, de 23 de enero de 1970, relativa a los medios de comunicación de masas y a los derechos del hombre, que recomendó al Comité de Ministros la creación de un consejo de expertos para estudiar la armonización de las normas de los Estados miembros en diferentes materias, entre las que se incluyó el derecho de rectificación.

13. De mayor trascendencia resulta la Resolución (74) 26, de 2 de julio de 1974, del Comité de Ministros, sobre el derecho de réplica ${ }^{12}$. Y es que, pese a carecer de carácter vinculante, supuso un importante paso para la armonización de las normas reguladoras del derecho de rectificación en los distintos Estados ${ }^{13}$. De hecho, ha tenido una notable incidencia en la configuración del derecho de rectificación en nuestro ordenamiento jurídico ${ }^{14}$. En el primer punto de su anexo señala que "todas persona fisica o jurídica, así como cualquier otra entidad, con independencia de su nacionalidad o residencia, que sea designada en un diario, un escrito periódico, en una emisión de radio o de televisión o por cualquier otro medio de comunicación de carácter periódico, y respecto de la cual hayan sido publicadas informaciones conteniendo hechos que ella considere inexactos, puede ejercer el derecho de respuesta con el fin de corregir los hechos que le aluden"; y en el punto segundo dispone que "a petición de la persona aludida, el medio de comunicación de masas está obligado a publicar la respuesta que esta persona le haya hecho llegar".

14. Posteriormente el Comité de Ministros del Consejo de Europa emitiría la Recomendación (84) 22, de 7 de diciembre de 1984, sobre la utilización de las capacidades de satélite para la televisión y radiofusión sonora, que en su artículo 4 establece que "se permitirá a toda persona fisica o jurídica, cualquiera que sea su nacionalidad o lugar de residencia, ejercer el derecho de rectificación o tener acceso a recursos similares, en relación con los programas a los que se refiere esta Recomendación".

${ }^{11}$ Vid. P. FARré LóPeZ, “El Derecho de rectificación en el Consejo de Europa”, La Ley, 4276, 2010, p. 1 (esta doctrina forma parte del libro "El derecho de rectificación. Un instrumento de defensa al poder de los medios", edición nº 1, Editorial La Ley, Madrid, octubre, 2008).

${ }_{12}$ Disponible en: https://www.coe.int/en/web/freedom-expression (fecha última consulta: 01/04/2020).

13 Vid. L.C. Bandrés OroñÉz, "El derecho de rectificación”, Diario La Ley, 8837, 2016, p. 10.

14 Tanto es así, que durante la elaboración de la Ley Orgánica 2/1984, de 26 de marzo, reguladora del derecho de rectificación, el Ministro de Justicia del momento, Ledesma Bartret, señalaba que dicha norma se inspiraba en la resolución $\mathrm{n}^{\circ} 26$ de 1974 del Comité de Ministros del Consejo de Europa (vid. L. Gutiérrez GoÑI, "Influencia de la Resolución (74) 26, del Comité de Ministros del Consejo de Europa, sobre la vigente regulación española del derecho de rectificación”, Actualidad Jurídica Aranzadi, 624, p. 1). 
15. Un lustro más tarde se adoptó el Convenio Europeo sobre Televisión Transfronteriza de 5 de mayo de $1989^{15}$, que en su artículo 8.1 dispone que "cada parte transmisora se asegurará de que toda persona fisica o jurídica, cualquiera que fuere su nacionalidad o lugar de residencia, pueda ejercer el derecho de réplica o tener acceso a otro recurso jurídico o administrativo equiparable con respecto a emisiones transmitidas o retransmitidas por organismos o con ayuda de medios técnicos que dependan de su jurisdicción".

16. Para cerrar este breve recorrido por la regulación supraestatal del derecho de rectificación voy a hacer una referencia al derecho de la Unión Europea. Al respecto, hay que empezar diciendo que la Carta de los Derechos Fundamentales de la Unión Europea, aprobada por el Parlamento Europeo, el Consejo y la Comisión el 7 de diciembre de $2000^{16}$, no incluye ninguna referencia al derecho de rectificación. Sin embargo, ello no significa que el ordenamiento comunitario haya permanecido totalmente ajeno al reconocimiento de este derecho.

17. La primera referencia al derecho de rectificación la encontramos en el Libro Verde sobre el establecimiento del mercado común de radiodifusión, especialmente por satélite y por cable, elaborado en el año 1984 por la Comisión Europea. En el mencionado texto, la Comisión aboga por la armonización de las normativas de los Estados miembros en la regulación del derecho de rectificación ${ }^{17}$.

18. Posteriormente, se aprobó la Directiva 89/552/CEE, de 3 de octubre, del Consejo, sobre coordinación de determinadas disposiciones legales, reglamentarias y administrativas de los Estados miembros relativas al ejercicio de radiodifusión televisiva ${ }^{18}$, que se refiere al derecho de rectificación en su artículo 23. Dicho precepto fue objeto de modificación por parte de la Directiva 97/36/CE, del Parlamento Europeo y del Consejo, de 30 de junio de 1997, por la que se modifica la Directiva 89/552/ $\mathrm{CEE}^{19}$, que le dio su redacción actual. En su primer punto señala que "sin perjuicio de las demás disposiciones civiles, administrativas o penales adoptadas por los Estados miembros, cualquier persona fisica o jurídica, independientemente de su nacionalidad, cuyos legítimos derechos, en particular por lo que atañe a su honor y su reputación, hayan sido lesionados como consecuencia de una alegación incorrecta hecha en un programa televisivo deberá poder disponer de un derecho de réplica o de medidas equivalentes". Además, en su tercer párrafo, dispone que "los Estados miembros adoptarán las disposiciones necesarias para establecer este derecho o estas medidas y determinar el procedimiento para su ejercicio".

19. No obstante, las anteriores Directivas únicamente se refieren al derecho de rectificación en el ámbito específico de la televisión ${ }^{20}$. Y lo mismo ocurre con la Directiva 2007/65/CE del Parlamento Europeo y del Consejo, de 11 de diciembre de 2007, por la que se modifica la Directiva 89/552/CE21, aunque este último texto recoge una novedad importante: introduce por primera vez una referencia al

\footnotetext{
${ }_{15}$ Disponible en: https://www.boe.es/diario_boe/txt.php?id=BOE-A-1998-9479 (fecha última consulta: 01/04/2020).

${ }_{16}$ Disponible en: https://www.europarl.europa.eu/charter/pdf/text es.pdf (fecha última consulta: 01/04/2020).

${ }_{17}$ Para ello, la Comisión proporciona una serie de directrices. Puede consultarse un extracto de las mismas en: L.C. BANDRÉS OROÑÉz, “El derecho de rectificación”, op. cit., pp. 7 y 8.

18 Disponible en: https://eur-lex.europa.eu/legal-content/ES/TXT/?uri=celex:31989L0552 (fecha última consulta: 01/04/2020).

19 Disponible en: https://eur-lex.europa.eu/legal-content/ES/TXT/?uri=celex\%3A31997L0036 (fecha última consulta: 01/04/2020).

${ }^{20}$ Ello, pese a que desde el Parlamento Europeo se venía reclamando desde largo tiempo atrás el establecimiento de un derecho de rectificación en todos los medios de comunicación. En este sentido, pueden destacarse dos Resoluciones: la de 12 de marzo de 1982, relativa a la televisión y a la radiodifusión en la Comunidad Económica Europea; y la de 16 de septiembre de 1991, sobre la concentración de los medios de comunicación y el pluralismo. En esta última Resolución solicitaba expresamente a la Comisión la presentación de una propuesta de Directiva que garantizara el derecho de rectificación en todos los medios de comunicación (punto 26).

${ }_{21}$ Disponible en: https://eur-lex.europa.eu/legal-content/ES/TXT/?uri=celex\%3A32007L0065 (fecha última consulta: 01/04/2020).
} 
posible ejercicio del derecho de rectificación en internet. Sin embargo, lo hace de una forma somera, limitándose a plantear la posibilidad de que el derecho de rectificación pueda resultar de aplicación también en internet: "el derecho de réplica es un recurso jurídico apropiado para la radiofusión televisiva y podría aplicarse también en el ámbito de los servicios en línea" (punto 53). Una posibilidad que, por otro lado, ya había sido planteada un año antes por la Recomendación del Parlamento Europeo y del Consejo de 20 de diciembre de 2006, relativa a la protección de los menores y de la dignidad humana y al derecho de réplica en relación con la competitividad de la industria europea de servicios audiovisuales y de información en línea22: "conviene que el derecho de réplica o los recursos equivalentes se apliquen a todos los medios de comunicación en línea y que se tomen en consideración las características respectivas del medio y del servicio" (punto 15). Además, este último texto dedica su anexo 1 al establecimiento de una serie de directrices para la aplicación, a escala nacional, de medidas para garantizar el derecho de rectificación en relación con los medios de comunicación en línea. Su objetivo es "instaurar, en la legislación o las prácticas nacionales de los Estados miembros, medidas destinadas a garantizar el derecho de réplica o recursos equivalentes en relación con los medios de comunicación en línea, teniendo debidamente en cuenta sus disposiciones legislativas nacionales y constitucionales y sin perjuicio de la posibilidad de adaptar su ejercicio a las particularidades de cada tipo de medio de comunicación".

20. Posteriormente, la Comisión aprobó la Directiva 2010/13/UE, del Parlamento Europeo y del Consejo, de 10 de marzo de 2010, de coordinación de determinadas disposiciones legales, reglamentarias y administrativas de los Estados miembros relativas a la prestación de servicios de comunicación audiovisual ${ }^{23}$. Aunque está referida de nuevo al ámbito específico de la televisión, insiste en que "el derecho de réplica es un recurso jurídico apropiado para la radiodifusión televisiva y podría aplicarse también en el ámbito de los servicios en línea".

21. Más recientemente, se adoptó el Reglamento (UE) 2016/679, del Parlamento Europeo y del Consejo, relativo a la protección de las personas físicas en lo que respecta al tratamiento de datos personales y a la libre circulación de estos datos y por el que se deroga la Directiva 95/46/CE ${ }^{24}$, y que es conocido como Reglamento General de Protección de Datos. No obstante, no se ha aprovechado la ocasión para dotar al derecho de rectificación de un marco jurídico uniforme en el espacio europeo. De hecho, el texto no recoge ninguna referencia al derecho de rectificación ante la publicación de informaciones erróneas o inexactas

\section{Dispersión normativa y falta de armonización de la regulación del derecho de rectificación en los ordenamientos nacionales}

22. Como hemos visto en el apartado anterior, las distintas iniciativas llevadas a cabo en el marco del Derecho Internacional no han fructificado en la creación de un derecho de rectificación universal y homogéneo; y ni siquiera en el ámbito europeo se ha conseguido la pretendida unificación normativa. Lejos de ello, la mayor parte de los textos se limitan a recomendar (en la mayoría de los casos) o a imponer a los Estados que incluyan este derecho en sus respectivos ordenamientos jurídicos.

23. Ante el fracaso de los organismos internacionales para introducir un derecho de rectificación de carácter universal, su regulación se encuentra dispersa en los ordenamientos nacionales, cada uno de los cuales lo ha configurado en un modo diverso.

\footnotetext{
${ }^{22}$ Disponibleen:https://eur-lex.europa.eu/legal-content/ES/TXT/?uri=urisehttps://eur-lex.europa.eu/legal-content/ES/TXT/?uri= uriserv:OJ.L_.2006.378.01.0072.01.SPA\&toc=OJ:L:2006:378:TOCrv:OJ.L_.2006.378.01.0072.01.SPA\&toc=OJ:L:2006:378:TOC (fecha última consulta: 01/04/2020).

${ }^{23}$ Disponible en: https://eur-lex.europa.eu/legal-content/ES/TXT/PDF/?uri=CELEX:32010L0013\&from=EN3\&from=EN (fecha última consulta: 01/04/2020).

${ }^{24}$ Disponible en: https://eur-lex.europa.eu/legal-content/ES/TXT/?uri=CELEX\%3A32016R0679 =EN3\&from=EN (fecha última consulta: 01/04/2020).
} 
24. Pero ello no quiere decir que los esfuerzos llevados a cabo para tratar de armonizar la regulación de los distintos Estados hayan resultado totalmente en balde. De hecho, es posible encontrar muchas analogías entre las diferentes regulaciones, precisamente gracias a esta labor armonizadora ${ }^{25}$. A modo de ejemplo, la mayor parte de los Estados de nuestro entorno (con alguna excepción ${ }^{26}$ ) admiten su ejercicio tanto en la vía prejudicial como judicial (en el caso de que la primera no resulte efectiva) ${ }^{27}$, reconocen este derecho en favor de las personas tanto físicas como jurídicas ${ }^{28}$, en general establecen plazos breves para su ejercicio ${ }^{29}$ y no exigen que el perjuicio sea efectivo para que pueda ejercitarse el derecho, bastando con que sea hipotético o probable ${ }^{30}$.

25. Sin embargo, todavía queda bastante camino por recorrer, pues existen muchas diferencias en la naturaleza, contenido y alcance que las normativas de los Estados han atribuido al derecho rectificación ${ }^{31}$. Como he adelantado, ni siquiera es uniforme la denominación que utilizan los distintos ordenamientos para referirse a este derecho. A modo de ejemplo, nuestro ordenamiento jurídico habla de derecho de rectificación ${ }^{32}$, al igual que ocurre con el Derecho italiano (diritto di rettifica). En Francia, Portugal y Alemania se habla de derecho de respuesta (droit de réponse, direito de resposta y Gegendarstellungsrecht, respectivamente). Y en los Estados anglosajones suele hablarse de derecho de réplica (right of reply) ${ }^{33}$. Tampoco coincide la jurisdicción competente para conocer de la acción de rectificación, ni la legitimación activa y pasiva, ni el contenido del propio derecho o los plazos para su ejercicio $^{34}$.

26. Como vengo señalando, en el marco actual, caracterizado por una creciente internacionalización de la información, esta dispersión normativa es susceptible de generar algunos problemas desde el punto de vista del Derecho Internacional Privado (a los que paso a referirme en el siguiente apartado); $\mathrm{y}$, además, las diferencias existentes entre los ordenamientos jurídicos de los distintos países conllevan una enorme inseguridad jurídica para los ciudadanos y dificultan enormemente el ejercicio transfronterizo del derecho de rectificación ${ }^{35}$.

${ }^{25}$ Sobre las analogías que presentan las regulaciones del derecho de rectificación en los diferentes Estados, vid. P. FARRÉ LÓPEZ, “Analogías entre los ordenamientos jurídicos tomados en consideración”, La Ley, 4286, 2010, p. 1 (esta doctrina forma parte del libro "El derecho de rectificación. Un instrumento de defensa al poder de los medios", edición nº 1, Editorial La Ley, Madrid, octubre, 2008).

${ }^{26}$ Vid. P. Farré LóPEZ, "Diferencias entre los distintos ordenamientos jurídicos”, La Ley, 4287, 2010, p. 2 (esta doctrina forma parte del libro "El derecho de rectificación. Un instrumento de defensa al poder de los medios", edición $\mathrm{n}^{\circ}$ 1, Editorial La Ley, Madrid, octubre, 2008).

${ }^{27}$ Este es el caso de los ordenamientos anglosajones y escandinavos, en los que no se reconoce un derecho de réplica o rectificación exigible judicialmente (Ibidem, p. 1).

${ }^{28}$ Ibidem, p. 3.

${ }^{29}$ Vid. P. FARRÉ LÓPEZ, “Analogías entre los ordenamientos jurídicos...”, op. cit., p. 1.

${ }^{30}$ Idem.

${ }^{31}$ Un problema al que hacía ya referencia hace varias décadas el Informe de la Comisión Internacional sobre problemas de la Comunicación de 1980 (Informe MacBride). Disponible en: https://unesdoc.unesco.org/ark:/48223/pf0000034156_spa (fecha última consulta: 01/04/2020).

${ }^{32}$ Con anterioridad a la entrada en vigor de la Ley Orgánica 2/1984, de 26 de marzo, reguladora del derecho de rectificación, nuestro ordenamiento también recogía, se distinguía entre el derecho de réplica, cuando la acción era ejercida por una autoridad, y el derecho de rectificación, cuando procedía de un particular (artículos 58 y 62 de la Ley de Prensa e Imprenta de 18 de marzo de 1966). Sin embargo, con la promulgación de la mencionada norma se unificó el sistema bajo un único derecho, al que se le dio la denominación de derecho de rectificación.

${ }^{33}$ Vid. P. FARré LóPez, "Rectificar y replicar", La Ley, 4272, 2010, p. 1 (esta doctrina forma parte del libro "El derecho de rectificación. Un instrumento de defensa al poder de los medios", edición n ${ }^{\circ}$ 1, Editorial La Ley, Madrid, octubre, 2008).

${ }^{34}$ Vid. P. FARré LóPEZ, "El Derecho de rectificación en el Consejo de Europa", op. cit., p. 4 y "Diferencias entre los distintos ordenamientos jurídicos", op. cit., pp. 1 y ss.

${ }^{35}$ Vid. P. FARRÉ LóPEz, "El Derecho de rectificación en la Unión Europea”, La Ley, 4277, 2010, p. 4 (esta doctrina forma parte del libro "El derecho de rectificación. Un instrumento de defensa al poder de los medios", edición no 1, Editorial La Ley, Madrid, octubre 2008). 


\section{El ejercicio transfronterizo de la acción de rectificación desde la perspectiva del Derecho In- ternacional Privado}

\section{Competencia judicial}

\section{A) Determinación de la competencia judicial internacional}

27. No encontramos en el ámbito del Derecho Internacional Privado una norma que establezca de forma específica cuál es el tribunal competente para conocer de las demandas que tienen por objeto la salvaguarda de los derechos de la personalidad, y, entre ellas, las relativas al derecho de rectificación, lo que nos obliga a acudir a las normas generales que resultan de aplicación en materia de responsabilidad extracontractual ${ }^{36}$. Al respecto, contamos con tres posibles instrumentos para aplicar en esta materia, en función de si el demandado está domiciliado en un Estado miembro de la Unión Europea, en un Estado del denominado territorio Lugano o en un tercer Estado ${ }^{37}$ :

28. En aquellos casos en los que el demandado tenga su domicilio en un Estado miembro de la Unión Europea, la competencia judicial vendrá determinada por el Reglamento (UE) 1215/2012, del Parlamento Europeo y del Consejo, de 12 de diciembre de 2012, relativo a la competencia judicial, el reconocimiento y la ejecución de resoluciones judiciales en materia civil y mercantil ${ }^{38}$ (en adelante: Bruselas I bis), pues así lo establece su artículo 5.

29. El Reglamento Bruselas I bis atribuye preferencia sobre el resto de foros a la sumisión de las partes, ya sea expresa o tácita (artículos 25 y 26), a excepción de los foros exclusivos. Como es sabido, dicha sumisión consiste en que las partes acuerden atribuir a un tribunal determinado la competencia para resolver los conflictos que puedan surgir entre ellas. Lo cierto es que en el caso que nos ocupa, al movernos en el ámbito extracontractual, normalmente no existirá dicho acuerdo previo de sumisión. No obstante, junto a la sumisión expresa también cabe la denominada sumisión tácita, que tiene lugar cuando el demandante decide interponer la demanda ante un tribunal determinado y el demandado comparece sin impugnar la competencia, en cuyo caso se considera que existe un pacto entre las partes para atribuir la competencia a dicho tribunal.

30. En defecto de sumisión expresa o tácita de las partes que atribuya la competencia a un tribunal determinado, el Reglamento Bruselas I bis establece el foro general del domicilio del demandado (artículo 4). Así, resultarán competentes los tribunales del Estado miembro en el que se encuentre domiciliado el medio de comunicación o la red social o servicio equivalente en el que se haya publicado la información que se pretende rectificar ${ }^{39}$. En el caso de que se trate de una persona jurídica (lo que en la práctica es muy habitual), se entenderá que está domiciliada en el lugar en que se encuentre: a) su sede estatutaria; b) su administración central, o c) su centro de actividad principal (artículo 63.1 del Reglamento Bruselas I bis).

31. Además, existe un foro especial por razón de la materia, previsto en el artículo 7.2 del Reglamento Bruselas I bis, que otorga competencia judicial internacional a los Tribunales del Estado miembro

36 Vid. A.L. Calvo Caravaca y J. Carrascosa González, Derecho Internacional Privado (volumen II), Granada: Comares, 2016, p. 1286. Vid. también: STJUE de 7 de marzo de 1995 -Fiona Shevill, Ixora Trading Inc., Chequepoint Sarl y Chequepoint International Ltd contra Presse Alliance SA-, disponible en: https:/eur-lex.europa.eu/legal-content/ES/ TXT/?uri=CELEX\%3A61993CJ0068 (fecha última consulta: 01/04/2020).

37 Vid. G. Palao Moreno, "Competencia judicial internacional en supuestos de responsabilidad civil en Internet", en AA.VV.: Cuestiones actuales de Derecho y tecnologías de la información y la comunicación, Navarra: Thomson-Aranzadi, 2006, pp. 275 y ss.; y P. OREJUdo PRIETO DE LOS Mozos, "La vulneración de los derechos de la personalidad en la jurisprudencia del Tribunal de Justicia", La Ley Unión Europea, 4, 2013, pp. 18 y ss.

${ }^{38}$ Disponible en: https://eur-lex.europa.eu/legal-content/ES/TXT/PDF/?uri=CELEX:32012R1215\&from= DE (fecha última consulta: 01/04/2020).

${ }^{39}$ Vid. J.M. Benito García, “El derecho de rectificación electrónica...”, op. cit., pp. 175 y 176. 
donde se haya producido o pueda producirse el hecho dañoso. Por tanto, el demandante podrá presentar la demanda, alternativamente, ante los tribunales del domicilio del demandado o ante los del lugar donde se haya producido o pueda producirse el daño.

32. El Tribunal de Justicia de la Unión Europea ha señalado que, cuando el Reglamento Bruselas I bis se refiere al lugar donde se haya producido o pueda producirse el hecho dañoso, incluye tanto el lugar del hecho causal como aquel en el que se verifica el resultado dañoso (STJUE de 25 de octubre de 2011 — caso eDate Advertising GmbH/X, Olivier Martinez, Robert Martinez/MGN Limited — ${ }^{40}$ ).

33. Pero cuando se trata de información difundida a través de internet, la determinación de la competencia con base en el lugar en el que se ha producido la verificación del hecho dañoso resulta más problemática, pues es frecuente que se produzcan daños en diferentes Estados ${ }^{41}, \mathrm{y}$, en concreto, en todos aquellos en los que la información sea o haya sido accesible y en los que la víctima pueda haber sufrido un ataque a su reputación. Ello plantea el interrogante de si es posible solicitar, ante los tribunales de un único Estado, que se publique la rectificación en todos aquellos lugares en los que haya estado accesible la información originaria; o si, por el contrario, ha de solicitarse la rectificación ante los tribunales de todos los Estados en los que se haya difundido la información.

34. Para responder a esta pregunta debemos acudir una vez más a la jurisprudencia del Tribunal de Justicia de la Unión Europea dimanante de su Sentencia de 25 de octubre de 2011 — caso eDate Advertising $\mathrm{GmbH} / \mathrm{X}$, Olivier Martinez, Robert Martinez/MGN Limited - ${ }^{42}$, en la que señala que, cuando los daños contra los derechos de la personalidad se producen en varios Estados, en aplicación del foro especial, la víctima puede interponer la acción de reparación, bien ante los órganos jurisdiccionales del Estado miembro en el que se encuentra su centro de intereses, para reclamar por la totalidad del daño causado; o bien ante los órganos jurisdiccionales de cada Estado parte en el que se hayan verificado los perjuicios, pero en este último caso, resultarían competentes para conocer únicamente de los daños producidos en dicho Estado.

35. Si aplicamos la mencionada doctrina de forma específica al derecho de rectificación, el resultado es que el perjudicado puede solicitar, ante los tribunales del Estado en el que se encuentre su centro de intereses, la rectificación de la información publicada en todos los Estados. En cuanto a la determinación del centro de intereses del perjudicado, en el caso de las personas físicas, se suele identificar, por lo general, con el lugar que corresponde a su residencia habitual; mientras que en el caso de las personas jurídicas se atiende al lugar donde la misma ejerce su actividad comercial principal, pues es allí donde su reputación puede verse más perjudicada por la difusión de una información errónea o inexacta ${ }^{43}$.

36. Respecto a la posibilidad de que el perjudicado se dirija ante los órganos jurisdiccionales de cada uno de los Estados miembros en los que la publicación haya sido difundida y en los que alegue haber sufrido un ataque contra su reputación, conocida como "tesis mosaico", creo que debería interpretarse de modo restrictivo. Y es que, como ponen de manifiesto Calvo Caravaca y Carrascosa González, una interpretación amplia implicaría que todos los tribunales del mundo serían competentes, debido al alcance mundial de los contenidos publicados en internet ${ }^{44}$. Por ello, siguiendo a los mencionados

\footnotetext{
40 TJCE $2011 \backslash 331$.

${ }^{41}$ Sobre los criterios de determinación del lugar en el que se ha producido el daño en estos supuestos, vid. más ampliamente: A.L. Calvo Caravaca y J. Carrascosa GonzÁlez, Derecho Internacional Privado (volumen II), op. cit., p. 1396 y ss.; A.P. Abarca Junco (et. al.), Derecho Internacional Privado, Madrid: Universidad Nacional de Educación a Distancia, 2016, pp. 661 y ss.; y C. Espluges Mota (et. Al.), Derecho Internacional Privado, Valencia: Tirant lo blanch, 2018, pp. 659 y ss.

${ }^{42}$ TJCE $2011 \backslash 331$.

${ }^{43}$ Vid. A. Moreno Sánchez-Moraleda, ¿En qué estado se ha producido el daño en el caso de publicación en internet de información inexacta?, Revista de Derecho Patrimonial, 45, 2018, p. 4

${ }^{44}$ Vid. A.L. Calvo Caravaca y J. Carrascosa González, Conflictos de leyes y conflictos de jurisdicción en internet, Madrid: Colex, 2001, pp. 110 y ss.
} 
autores, considero que la interpretación más razonable es que no serán competentes los tribunales de aquellos países en los que no se haya producido (ni pueda producirse) perjuicio alguno, lo que, llevado al derecho de rectificación, supone que no tendrán competencia los tribunales de los Estados con los que el sujeto perjudicado no tenga ningún tipo de vínculo, no ejerza ningún tipo de actividad profesional y carezca de proyección pública, puesto que no parece que su derecho al honor sea susceptible de resultar lesionado en dichos lugares.

37. Por otro lado, si el demandado no está domiciliado en ningún Estado miembro, pero tiene su domicilio en uno de los Estados del denominado territorio Lugano (Islandia, Noruega y Suiza), será de aplicación el Convenio relativo a la competencia judicial, el reconocimiento y la ejecución de resoluciones judiciales en materia civil y mercantil, hecho en Lugano el 30 de octubre de $2007^{45}$ (en adelante: Convenio de Lugano), tal y como dispone su artículo 4. Al igual que hemos visto para el Reglamento Bruselas I bis, el Convenio de Lugano atribuye preferencia sobre el resto de foros a la sumisión de las partes (artículos 23 y 24). En defecto de sumisión expresa o tácita de las partes que atribuya la competencia a un tribunal determinado, establece el foro general del domicilio del demandado (artículo 2). Y, nuevamente, encontramos un foro especial por razón de la materia: el lugar del hecho dañoso (artículo 5.3). Para su determinación, me remito a lo expuesto unas líneas más arriba.

38. Por último, en caso de que el demandado tenga su domicilio en un Estado que no sea miembro de la Unión Europea y no se encuentre tampoco en el denominado territorio Lugano, para determinar si los tribunales españoles son competentes habrá que acudir a la Ley Orgánica 6/1985, del Poder Judicial (en adelante: LOPJ), pues tanto el Reglamento Bruselas I (artículo 6.1) como el Convenio de Lugano (artículo 4.1) se remiten a la normativa interna de cada Estado ${ }^{46}$. Ahora bien, ello será así siempre que no nos encontremos ante alguna de las excepciones previstas en el artículo 6.1 del Reglamento Bruselas I y en el artículo 4.1 del Convenio de Lugano (entre las que se encuentra la sumisión de las partes a un tribunal determinado). Por lo demás, téngase en cuenta que, a diferencia del Reglamento Bruselas I bis y del Convenio de Lugano, la LOPJ nos permite determinar únicamente si los tribunales españoles son o no competentes, es decir, no identifica el tribunal que resulta competente en caso de que no lo sean los españoles.

39. Descendiendo a las reglas concretas de determinación de la competencia, el artículo 22 ter.1 LOPJ establece el foro general del domicilio del demandado. No obstante, en la práctica dicho foro no entrará en juego, ya que, si el demandado está domiciliado en España, al tratarse de un Estado miembro de la Unión Europea, resultará de aplicación el Reglamento Bruselas I bis Sin embargo, la LOPJ también prevé un foro especial en razón de la materia: el lugar del hecho dañoso (artículo 22 quinquies.1.b)). Este foro especial sí podrá resultar operativo, en concreto, en aquellos casos en los que el demandado se encuentre domiciliado en un tercer Estado y el daño se haya producido en España. Ello, siempre que las partes no se hayan sometido expresa o tácitamente a los tribunales españoles o de cualquier otro Estado de la UE o del territorio Lugano, pues en ese caso entrarían en juego los foros de los artículos 25 y 26 del Reglamento Bruselas I bis o los artículos 23 y 24 del Convenio de Lugano, respectivamente.

40. Antes de cerrar este apartado resulta de interés hacer una referencia a la Resolución del Instituto de Derecho Internacional "Internet and the Infringement of Privacy: Issues of Jurisdiction, Applicable Law and Enforcement of Foreign Judgments", de 31 de agosto de $2019^{47}$, a través de la cual se propone una armonización de las normas de Derecho Internacional Privado de los diferentes Estados para la determinación de la competencia judicial internacional en relación a los supuestos de vulneración de los derechos de la personalidad a través de internet. La mencionada Resolución otorga preferencia sobre el resto de foros a la sumisión de las partes (artículo 6). En defecto de sumisión de las partes que

\footnotetext{
${ }^{45}$ Disponible en: https://eur-lex.europa.eu/legal-content/ES/TXT/PDF/?uri=CELEX:22007A1221(03)\& from=EN (fecha última consulta: 01/04/2020).

${ }^{46}$ Vid. A.P. Abarca Junco (Et. AL.), Derecho Internacional Privado, op. cit., pp. 664.

${ }^{47}$ Disponible en: www.idi-iil.org/app/uploads/2019/09/8-RES-EN.pdf (fecha última consulta: 01/04/2020)
} 
atribuya la competencia a un tribunal determinado, establece cuatro foros alternativos: el lugar donde se origine el daño, el domicilio del demandado, el lugar donde se produzcan o puedan producirse los daños más extensos y el domicilio del demandante, siempre que el material publicado fuera accesible en dicho Estado (artículo 5.1). La interposición de la demanda en cualquiera de los Estados competentes en virtud de lo anterior permitiría obtener la reparación de los daños que se hubieran producido o pudieran producirse en todos los Estados. (artículo 3.1).

\section{B) Determinación de la competencia interna de los tribunales españoles}

41. En cuanto a la competencia interna, el artículo 52.1.6 de la Ley de Enjuiciamiento Civil (en adelante: Lec.), establece que, en materia de derecho al honor, a la intimidad personal y familiar y a la propia imagen y, en general, en materia de protección civil de derechos fundamentales, será competente el tribunal del domicilio del demandante, y cuando no se encuentre en territorio español, el tribunal del lugar donde se hubiera producido el hecho que vulnere el derecho fundamental de que se trate.

42. No obstante, la competencia interna para conocer de la acción de rectificación ha sido expresamente prevista por la LODR, que, en virtud del principio de especialidad, resulta de aplicación preferente. El artículo 4 de dicha norma atribuye la competencia al Juez de Primera Instancia del domicilio del perjudicado o al del lugar donde se encuentre el domicilio del medio de comunicación (o de la red social o servicio equivalente) en que se haya publicado la información, pudiendo optar el perjudicado entre uno u otro. En caso de que la competencia no pueda determinarse mediante la aplicación de dicho precepto (lo que ocurrirá cuando demandante y demandado se encuentren domiciliados en un tercer Estado, pero el daño se haya producido en España), acudiremos con carácter supletorio a la regla general contenida en el artículo 52.1.6 Lec., y, por ende, resultará competente el tribunal del lugar en el que se haya producido el daño.

43. En cualquier caso, si el juez se considera incompetente, por haberse presentado la demanda ante un tribunal distinto del competente en virtud de las normas mencionadas en el párrafo precedente, de oficio y sin audiencia del demandado, dictará auto no admitiendo a trámite la demanda (artículo 5.2 LODR) e indicando el órgano al que corresponde el conocimiento del asunto (artículo 5.3 LODR). En ese caso, el perjudicado podrá dirigir su demanda al órgano competente dentro de los siete días hábiles siguientes al de la fecha de notificación de la resolución.

\section{Ley aplicable}

44. Respecto a determinación de la ley aplicable, no está prevista en ningún Tratado Internacional y tampoco en la normativa comunitaria. De hecho, el Reglamento (CE) 864/2007, del Parlamento Europeo y del Consejo, de 11 de Julio de 2007, relativo a las obligaciones extracontractuales ${ }^{48}$ (en adelante: Roma II) excluye de su ámbito de aplicación las obligaciones extracontractuales que se deriven de la violación de la intimidad o de los derechos relacionados con la personalidad (artículo 1.2.g)).

45. Aunque ha habido alguna iniciativa para regular de forma específica las reglas de determinación de la ley aplicable en el ejercicio de la acción de rectificación, lo cierto es que no han prosperado. Sin ir más lejos, el artículo 30 del Reglamento Roma II establecía la obligación de que "a más tardar el 31 de diciembre de 2008, la Comisión presentará al Parlamento Europeo, al Consejo y al Comité Económico y Social Europeo un estudio sobre la situación en el ámbito de la ley aplicable a las obligaciones extracontractuales derivadas de la violación de la intimidad y de los derechos relacionados con

${ }^{48}$ Disponible en: https://eur-lex.europa.eu/legal-content/ES/TXT/?uri=CELEX\%3A32007R0864 (fecha última consulta: 01/04/2020). 
la personalidad, teniendo en cuenta las normas sobre la libertad de prensa y la libertad de expresión en los medios de comunicación, y las cuestiones sobre conflicto de ley relacionadas con la Directiva 95/46/ CE del Parlamento Europeo y del Consejo, de 24 de octubre de 1995, relativa a la protección de las personas fisicas en lo que respecta al tratamiento de datos personales y a la libre circulación de estos datos"; una obligación que no se ha cumplido. Además, el 2 de mayo de 2012, el Parlamento Europeo emitió un Informe con recomendaciones destinadas a la Comisión sobre la modificación del Reglamento (CE) 864/2007, del Parlamento Europeo y del Consejo, de 11 de Julio de 2007, relativo a las obligaciones extracontractuales ${ }^{49}$, en el que pretendía introducir un artículo 5 bis, cuyo cuarto párrafo preveía que "la ley aplicable al derecho de réplica o medidas equivalentes y a toda medida preventiva o demanda por perjuicios contra un editor u organismo de radiodifusión respecto al contenido de una publicación o emisión y respecto a las violaciones de la privacidad o de los derechos relacionados con la personalidad derivadas del tratamiento de datos personales será la del país en que el emisor o editor tenga su residencia habitual". Sin embargo, esta propuesta tampoco se ha materializado en la práctica. Así mismo, cabe mencionar en este punto, una vez más, la Resolución del Instituto de Derecho Internacional "Internet and the Infringement of Privacy: Issues of Jurisdiction, Applicable Law and Enforcement of Foreign Judgments", de 31 de agosto de 2019, que atribuye preferencia al acuerdo de elección de ley adoptado por las partes (artículo 8), y, en defecto de acuerdo, propone como norma de conflicto la ley interna del foro (artículo 7), con algunas excepciones ${ }^{50}$.

46. Así las cosas, y ante la ausencia de una norma internacional que regule la determinación de la ley aplicable en estos supuestos, habrá que atender a las normas de conflicto del foro ${ }^{51}$. En el ordenamiento español, esta cuestión está prevista en el artículo 10.9.1 del Código Civil, que señala que "las obligaciones no contractuales se regirán por la ley del lugar donde hubiere ocurrido el hecho de que deriven". Si atendemos al tenor literal del precepto, cabría deducir que la ley aplicable al derecho de rectificación será la del lugar desde el que se haya publicado la información que se pretende rectificar. El problema es que cuando se trata de informaciones emitidas a través de internet, puede resultar complicado determinar desde donde se han publicado exactamente. Por ello, siguiendo a Calvo Caravaca y Carrascosa González, creo que lo más oportuno es llevar a cabo una interpretación flexible del artículo 10.9.1 del Código Civil e incluir el lugar donde se produce el daño, lo que, aplicado a nuestro estudio, nos conduce a la ley del lugar en el que se difunde la información ${ }^{52}$.

47. En caso de que la información publicada esté accesible en diferentes Estados (que resulta lo más habitual en la práctica), parece que lo razonable es aplicar la ley del país donde se ha producido el mayor daño, que normalmente será el país de residencia habitual del perjudicado, pues es el lugar en el que su fama y reputación puede resultar dañada en mayor medida. Ello permitirá la aplicación de la ley española cuando la persona perjudicada tenga su residencia habitual en España.

\footnotetext{
${ }^{49}$ Disponible en: https://www.europarl.europa.eu/sides/getDoc.do?pubRef=-//EP//TEXT+REPORT+A7-2012-0152+0+DOC +XML+V0//ES (fecha última consulta: 01/04/2020).

${ }^{50}$ Si resultara competente el tribunal del del domicilio del demandado y en el momento del perjuicio dicho domicilio se encontrara en otro Estado, la ley aplicable sería la ley interna del Estado que, considerando todas las circunstancias, tuviera la conexión más estrecha y significativa; si resultara competente el tribunal del lugar donde se hubiera producido o pudiera producirse el daño y la persona agraviada probara que el comportamiento crítico de la persona cuya responsabilidad se alega se produjo en otro Estado, la ley interna de este último Estado regiría todas las cuestiones de fondo, siempre que la persona agraviada solicitara formalmente la aplicación de esa ley y, a petición del tribunal, estableciera el contenido de la misma; si resultara competente tribunal del domicilio del demandante y la persona cuya responsabilidad se invoca demostrara que los efectos perjudiciales más amplios se produjeron en otro Estado, la ley interna de este último Estado regiría todas las cuestiones de fondo, siempre que esa persona solicitara formalmente la aplicación de esa ley y, a petición del tribunal, estableciera el contenido de la misma; y, por último, si la competencia del tribunal se basara en un acuerdo válido de elección de foro y ese tribunal estuviera situado en un Estado distinto de los que resultan competentes en virtud del artículo 5, la ley aplicable sería la del Estado que, considerando todas las circunstancias, tuviera la conexión más estrecha y significativa.

${ }^{51}$ Vid. A. Moreno Sánchez-Moraleda, “¿En qué estado se ha producido el daño en el caso de publicación en internet...”, op. cit., p. 4; y A.L. Calvo Caravaca y J. Carrascosa González, Derecho Internacional Privado (volumen II), op. cit., p. 75.

52 Vid. A.L. Calvo Caravaca y J. Carrascosa González, Derecho Internacional Privado (volumen II), op. cit., pp. 1403 y 1404. Vid. también en el mismo sentido: A.P. ABARCA JunCo (et. al.), Derecho Internacional Privado, op. cit., pp. 676 y 677 y ss.
} 


\section{A modo de conclusión}

48. La internacionalización de las comunicaciones, favorecida por la notable expansión que ha experimentado internet en los últimos años, exige repensar la regulación actual del derecho de rectificación. En este sentido, sería conveniente crear un derecho de rectificación universal; $\mathrm{y}$, entre tanto, resulta ineludible avanzar en la labor armonizadora de las normativas de los distintos Estados con el objetivo de unificar criterios legislativos.

49. De hecho, la comunidad internacional parece ser consciente de ello, y, desde diferentes foros internacionales, se han aprobado varios textos recomendando la armonización de las regulaciones estatales. No obstante, lo cierto es que no se han conseguido grandes avances y todavía son muchas las diferencias existentes en la regulación del derecho de rectificación en los ordenamientos jurídicos de los distintos Estados. Ello provoca inseguridad jurídica y plantea algunos problemas desde el punto de vista del Derecho Internacional Privado.

50. Y es que, tampoco encontramos en los diferentes textos supranacionales de Derecho Internacional Privado ninguna norma que regule de forma expresa el derecho de rectificación, lo que ha exigido una importante labor hermenéutica por parte de la jurisprudencia y de la doctrina, que, como hemos visto, han tratado de aportar soluciones para clarificar el sistema. Sería deseable, en cualquier caso, que se acometieran las oportunas reformas legislativas con el objeto de introducir reglas específicas para la determinación de la competencia judicial y de la ley aplicable en el ejercicio transfronterizo de la acción civil de rectificación. 